\title{
“ALEXIS": EL DEBATE QUE NO CESA
}

\section{M." del Carmen FERNÁNDEZZ DIAZ}

Universidad de Santiago de Compostela

Sabido es que el conjunto de la obra de Marguerite Yourcenar constituye una reflexión fillosófica y metafísica sobre la relación entre el cuerpo y el espíritu, la materia y una hipotética "esencia" que la transciende. La mayor parte de los protagonistas de sus relatos gozan y sufren con el sentimiento amoroso, máximo exponente de esta dicotomía primaria. Así sucede en el caso de Alexis o en el de Adriano, en el de Zenón o en el de Nathanaël. El sufrimiento surge en el momento mismo en que pretenden separar la sentimentalidad y el placer, escindir la materia del espíritu, en el instante en que comprenden que sus tendencias innatas chocan con la moral establecida. La "solución" que van a encontrar es muchas veces la de abandonarse a la voluptuosidad" que ven como pecaminosa - al menos en el caso de Alexis intentando eliminar todo atisbo de emotividad en esos encuentros pasajeros. Yourcenar considera que dicha opción es errónea y en "Alexis o el Tratado del Inátil Combate' será la misma autora quien subraye la equivocada conducta de su personaje: "Podriamos responderle a Alexis que la voluptuosidad apartada de esa manera corre el riesgo de convertirse también en aburrida rutina"!.

Esta aseveración corresponde al contenido del relato: La extensa confesión de Alexis a Mónica, su esposa, se esfuerza en asegurar en todo momento que el amor ha estado ausente en sus diversas aventuras extra-matrimoniales llegando incluso a afirmar que no recuerda ni los nombres de quienes se han ido cruzando en su camino. Yourcenar pone de manifiesto que esa actitud de su personaje no hace más que seguir una moda que anula toda sentimentalidad y que reacciona así contra todo atisbo del excesivo carácter almibarado de la época romántica. Pero existe, sin lugar a dudas, otra motivación más profunda en la manera de excusarse de Alexis y proviene del complejo de culpa que lo domina.

El remordimiento que acompaña cada una de sus "caidas" excluye cualquier posibilidad de una realización plena del yo, ausente también en su ma-

' Cf. M. YOURCENAR, Alexis o el tratado del inuitil combate. Ed. Alfaguara, Madrid, 1996, prólogo, 20. 
trimonio. En sus relaciones masculines tratarå de negar cualquier sentimiento y, al mismo tiempo, en la intimidad de su hogar echará en falta la fogosidad de la pasión, del deseo. El conjunto del libro va a constituirse asi en un alegato a favor de la intrínseca unidad del hombre, unidad que impide separar -como lo ha hecho la ética judeo-cristiana- sus dos caras. "Alexis..." se convierte así en uno de los primeros exponentes de la sorda lucha de Marguerite Yourcenar por demostrar a lo largo de toda su obra que uno de los mayores errores de Occidente ha consistido en desgajar la materia del espíritu, y que da ahi proceden muchos de sus males: "Uno de los errores irreparables del Occidente fue probablemente el de conceptuar la compleja sustancia humana bajo la forma antitética alma-cuerpo, y no salir después de esta antítesis, a no ser negando el alma".2.

\section{LA INFLUENCIA DE RILKE Y DE GIDE}

Alexis se nos presenta como un personaje profundamente dividido y totalmente infeliz, ignorante de que "el amor es conocimiento y también saber serenar y orientar al gran Dios-Río oculto y culpable de la sangre, como decía Rilke"', y no olvidemos que Yourcenar confesó haberse inspirado directamente en el escritor checo a la hora de componer su relato: "Lo que encuentro en más de una pógina (y quizá en exceso) es la influencia grave y patética de Rilke, al que una feliz castualidad me hizo conocer muy pronto"".

En Los Cuadernos de Malle Laurids Brigge, (1094-19/0) Rilke trata un tema similar hasta cierto punto: Se trata de una acumulación de recuerdos de Malte, personaje de ficción y autor apócrifo de los citados cuademos. Malle es un ser frustrado, angustiado ante la vida, que se sumerge en el recuerdo de un infancia misteriosa, dominada por la añoranza de una joven, reflejo del ideal. También Alexis sueña con que Mónica pueda "salvarlo", pero pronto percibe que no hay redención posible, ni siquiera a través de la paternidad: Habiamos ido retrasando, por una especie de tácito acuerdo el instante en que nos perteneceríamos del todo uno al otro. Pensaba en ello con un poco de inquietud y de repugnancia ${ }^{5}$.

Imposible no evocar a Gide a través de estas frases, imposible no recordar sus Cuademos de André Walter (1891), en los que asistimos a las indeci-

${ }^{2}$ Cf. M.YOURCENAR, El tiempo, gran escultor, Alfaguara, Madrid, 1989, 210.

'CF. C.GURMENDEZ, Estudios sobre el amor, Anthropos, Barcelona, 1991, 222.

‘CI. M. YOURCENAR, Alexis..., o.c., 22.

${ }^{5}$ Cf. M.YOURCENAR, Alexis..., o.c., 137. 
siones del protagonista entre sus inclinaciones naturales y las imposiciones de la moral establecida o El tratado del vano deseo y, en general, la mayor parte de su producción. Nunca negó Marguerite Yourcenar la influencia de Gide.

La solución ya la conocemos: tratar de desvincular toda emoción, todo sentimiento en los encuentros ocasionales y sin duda ésa será también la mayor desdicha de Alexis: He huido de las ataduras de las costumbres, hechas de ternura ficticia, de engaño sensual y hábito perezoso. Creo que sólo hubiera podido amar a un ser perfecto y yo soy demasiado mediocre para merecer que me aceptara?. Esta renuncia "a priori" de una dicha amorosa posible pone de relieve un complejo de culpa y no tanto una inseguridad manifiesta. La búsqueda de una perfección integra, que de antemano reconoce inalcanzable, es una excusa para no involucrarse emocionalmente. Lo que sucede es que todo aquello que se rechaza, según Freud, termina por adquirir dimensiones desmesuradas y patológicas. La represión desencadena trastornos de la personalidad o psiconeurosis. Si lo que se niega, como en el caso de Alexis, es una tendencia innata hacia la homosexualidad, ésta última terminará por triunfar tarde o temprano, no sin crear al mismo tiempo un profundo desequilibrio interior.

\section{EL PLATONISMO}

La homosexualidad y su valoración o menosprecio social han sido conceptos fluctuantes a lo largo de la historia. Yourcenar asi lo manifestó en numerosisimas ocasiones. En su intento por crear una teoría del equilibrio humano, retrocede al amor platónico, tal como aparece en El Banquete. Es de sobra conocido que en el platonismo, que tan bien conocía la autora, el amor era concebido como un medio de acceso a la Belleza, sólo posible a través del goce del ser amado, que actuaría como medium, como vehículo de elevación del amante desde lo sensible hasta lo espiritual. Es este concepto de amor el que reivindica la escritora belga, independientemente de que la pareja sea o no heterosexual.

Alexis, en todas sus manifestaciones, buscará ese equilibrio, esa armonía que no logra encontrar y que ya está presente en el pensamiento platónico cuando describe el amor como "acorde" y música, en cuanto que armonía. También Alexis busca a través de la música esa autoaceptación y esa paz in-

"Cf. D.LEUWERS, Alexis ou naissance et rupture", en Actes du Colloque Intermational, Valencia Univ., 1984, 143.

${ }^{7}$ Cf. M.YOURCENAR, Aleris,..., o.c., 93-94. 
terior que le es negada por unos valores sociales en clara disonancia con sus más intimas inclinaciones. Si alguna vez consigue ese equilibrio anhelado será precisamente cuando observe sus manos sobre el teclado y la etérea fusión de todo su ser con el instrumento musical: $Y$ fue en aquel momento cuando se me aparecieron mis manos. Reposaban sobre las teclas... Me parecfan de repente extraordinariamente sensitivas; incluso inmóviles parecian rozar el silencio como para incitarlo a revelarse en acordes... Hablan anudado alrededor de los cuerpos la breve alegría de los abrazos; hablan palpado, en los teclados sonoros, la forma de las notas invisibles; habian, en las tinieblas, encerrado con una caricia el contacto de los cuerpos dormidos. Alexis llega a aceptarse a través de la música, de la auto-percepción de su propio cuerpo. También los protagonistas de Gide llegarán a similar conclusión en un momento dado. Recuperan todos ellos, de ese modo, el concepto de belleza platónica. Frente a su piano, Alexis se maravilla de volver a encontrarse con su cuerpo, y eso le cura de pronto de tener un alma-el alma que no tarda en encontrar el fantasma del pecado-y de la que el héroe se desprende al fin".

En El Banquete, Platón establece una jerarquización: El amor entre hombres es considerado superior al heterosexual, ya que incluye el reconocimiento de una igualdad y de una espiritualidad común, mientras que el amor heterosexual está destinado únicamente a la procreación. Es además el amor, para Platón, un intento de acercamiento a la divinidad. Algo similar sucede con Yourcenar, que lo considera como un medio de conocimiento y de fusión con la naturaleza, con el cosmos y con el principio divino que lo haya creado, independientemente del nombre que reciba en los diferentes credos.

Gide, con el que la autora mantuvo múltiples entrevistas, justifica en la mayor parte de su producción literaria esa tendencia innata hacia la homosexualidad. Otro tanto sucede con Yourcenar que dedicará muchas páginas a defender el derecho irrenunciable a la expresión personal e integra del ser humano. Mucho ha cambiado la consideración social de este tema delicada desde la Grecia clásica hasta la actualidad. Cuando se publicó Alexis... (1929) la autora estaba reivindicando lo que hasta entonces se habla tratado de ocultar celosamente. Muchos años después todavía constataba que viendo las reacciones que aún hoy provoca, este relato parece haber conservado su actualidad e incluso ser de utilidad para algunos ${ }^{10}$.

\footnotetext{
Cf. M. YOURCENAR, Alexis..., o.c., 161-162.

${ }^{9}$ Cf. D. LEUWERS. o.c., 147.

${ }^{10}$ Cf. M. YOURCENAR, Alexis..., o.c., 14.
} 
En nuestra época todavía se trata la homosexualidad como una patología debida a trastornos endocrinos o hereditarios ${ }^{14}$, aunque cada vez con mayor insistencia se tienda a retirarle toda connotación enfermiza y a considerarla con mayor tolerancia. Esta aceptación social depara una distensión del hombre o mujer cuya tendencia sexual no se ajusta a los cánones establecidos. Para Yourcenar es única y exclusivamente un problema de tolerancia, a la vez que un derecho inalienable: Quizá no se haya reparado bastante en que el problema de la libertad sensual, en lodas sus formas, es en gran parte un problema de libertad de expresion ${ }^{12}$.

\section{EL TANTRISMO}

Aparte de invocar la manera de ver el amor que presenta la filosofia platónica, Yourcenar añade a la herencia griega las prácticas erótico-religiosas del tantrismo. Esta doctrina hindú, que tan bien conocia, pone de relieve la unión de lo sagrado con el amor humano y físico, noción extraña para la mentalidad occidental. En el hinduismo, por el contrario, existe una sacralización del erotismo similar a la que se conceptualizaba en la Grecia antigua, aunque con ciertos matices distintivos. En la mitologla hindú, el cosmos nació de la uniỏn de Shiva -la energía masculina-y de Shakti-la energía femenina-: ambos formaban un solo cuerpo a la vez masculino y femenino. Es precisamente esta unión perfecta la que el "tantrika", el adepto al tantrismo, trata de revivir. Para él, el cuerpo humano-microcosmos-es la exacta reproducción del imiverso- macrocosmos. ${ }^{13}$.

Si nos fijamos en las prăcticas tántricas, los amores pederastas de Adriano, resultan bastante más diáfanos y conllevan un ritual de conocimiento que los moralistas han condenado y en modo alguno comprendido ${ }^{14}$. El tantrismo borra la oposición entre sexo y espiritualidad. Según la propia autora, los procedimientos eróticos del tantrismo no tienden, como los del Tao, a asegurar al hombre vigor y longevidad (...) más bien se esfuerzan por dar un aspecto sagrado a la unión carnal, que el Occidente no ha conocido nunca ni ha querido aceptar's. La relación sexual es vista, para el iniciado,

"Vid. M. FOUCAULT, Histoire de la sexualité, Vol. Il, (3 vols.), Ed. Gallimard, París, 1984.

${ }^{12} \mathrm{Cf}$, M.YOURCENAR, Alexis..., o.c., 15.

"Vid. J. BRENET, "Tuntrisme. Le sexe et le sacré", Actualité des Religions, $\mathrm{n}^{\text {" }}$ $15,2000,54$.

"Vid. T.SANZ, Cómo leer a Marguerise Yourcenar, Ed. Júcar, Madrid, 1991, 44.

is Cf. M. YOURCENAR, "Aproximación al Tantrismo", en El tiempo..., o,c., 211. 
como un sacrificio ofrecido a la divinidad y un medio para alcanzar la beatitud suprema. Algo similar buscaba la teoría platónica, la consecución de un Absoluto, de una Belleza superlativa, y algo muy parecido sucede en el caso de Yourcenar: el amor conduce a una unión con el Absoluto, a una vía de acceso a lo sagrado, una iniciación en la que no están ausentes pruebas rigurosas de dolor, como si amar fuese un castigo a no haber podido quedarnos solos, como dice en Fuegos. Carne y espíritu han de ir entrelazados. Así lo expresa Zenón en Opus Nigrum: "La carne, en su audacia, hace suyas las curiosidades del espiritu"16.

\section{LA INFLUENCIA DE SCHOPENHAUER}

En Alexis..., Mónica representa el concepto tradicional del amor, como sucede con la mayor parte de los personajes femeninos de la autora. Ella representa en cierta medida el matrimonio con sus normas. No debemos pensar no obstante que este papel constituya según Yourcenar la esencia misma de las ambiciones emocionales femeninas, sino al contrario: la mujer ha heredado unos patrones de conducta que sufre y asume en silencio. Se trata en todo caso de denunciar el lugar secundario que la sociedad varonil le ha asignado. Alexis, educado entre mujeres, las respeta y las comprende, aunque no pueda amarlas en el sentido pasional. Y muchas veces reconoce que la sociedad les ha impedido la expresión de sus deseos más profundos: Las costumbres no permiten a la mujer la pasión; sólo se les consiente el amor; quizá por eso amen tan totalmente ${ }^{17}$.

Por otra parte, fracasa en su papel de "intermediaria". Para el tantrismo, la mujer es el instrumento que permite al adepto su aproximación a la beatitud. Esta paz, que también busca Alexis en Mónica no llega a alcanzarla. Ella se aproxima bastante más al papel de generadora de vida, de madre y no llega a alcanzar un estadio superior de compañera. Representa el orden social, en modo alguno la vía de una posible satisfacción de los más profundos anhelos de sus esposo. Y ella será no obstante la destinataria de su angustiosa confesión. El amor que Alexis siente por Mónica es una especie de ágape, en el sentido evangélico del término, en el que prima la simpatía y no la pasión. Este amor despojado de sensualidad fue descrito también por otro pesimista, Schopenhauer, tan próximo a Yourcenar en muchos aspectos. El filósofo alemán tiene como meta principal de su sistema ideológico la completa extinción de la voluntad, que conduce al logro de una especie de "nirvana", estado

${ }^{16}$ Cf. M. YOURCENAR, Opus Nigrum, Ed. Alfaguara, Madrid, 1985, 205.

"CF. M. YOURCENAR, Alexis..., o.c., 139. 
en el que el individuo alcanza la paz y encuentra la salvación. Schopenhauer también sitúa la Belleza como bien último y supremo. No hay que olvidar su teoría sobre la música, que ha ejercido gran influencia sobre la historia de la teoría estética, y su preocupación por la filosofía oriental.

La teoría hindú del nirvana, consistente en sentir compasión por todos los seres vivos, constituye en cierta medida una visión unitaria del mundo: Amar a todos los seres puros, como si fuesen intocables, llegar a la total supresión de la codicia amorosa, confundirse con la totalidad viviente es para el hindú el amor, la vida eterna por sí misma". Esta supresión de la voluntad, del deseo es algo que no da resultado en el caso de Alexis, siempre dividido y en constante búsqueda de su identidad. De modo que la influencia de Schopenhauer, en este caso, se refleja bastante más en el concepto de angustia que en aquel otro que insiste en una beatitud también alcanzable. Pone así de relieve la autora que no basta con el ágape, con el amor despojado de sensualidad, ni tampoco en el simple eros aislado, sino que en su fusión radica el bienestar.

\section{PINDARO: EL CUERPO Y LA VOLUNTAD}

En la redacción de Alexis...., según la propia autora, no fue desdeñable la influencia de Pindaro, al que reconoce como un precedente. Encuentra en sus poemas la idea de que sólo la divinidad acaba cada cosa según su esperanza. El hombre, ser efímero, es un juguete en sus manos. Frente a esta última reflexión, Yourcenar opone sin embargo la libertad humana, que no tiene por qué conformarse pacientemente con su suerte, ni plegarse ante un destino que reduzca sus inquietudes e intente domeñar sus impulsos. Pindaro, poeta de los atletas de los juegos olímpicos, de la libertad y del cuidado del cuerpo se convierte, precisamente por eso, en un precedente del humanismo entendido como canto a la perfección del ser humano, y no podía faltar en la percepción neorrenacentista de la autora' ${ }^{19}$.

El tiempo y el destino del hombre son, en realidad, los grandes temas de Alexis... La eternidad, temida y puesta en duda a la vez, aparece en muchas de sus páginas; es la eternidad prometida por la ética judeo-cristiana, el paraíso prometido a aquellos que no transgredan la norma que fija el concepto de pecado irremediablemente unido a la concupiscencia: Un día en que me sentí más valiente y tú más dulce que de costumbre, te confesé que tenía miedo a condenarme. Sonreiste gravemente para darme confianza. Entonces, brus-

"Cf. C. GURMENDEZ, o.c., 167.

"Vid. J.BLOT, Marguerite Yourcenar, Seghers, París, 1971, 50. 
camente, aquella idea me pareció pequeña, miserable y muy lejos; comprendi, aquel día, la indulgencia de Dios ${ }^{20}$. Siempre supo diferenciar la autora lo sagrado de lo meramente humano $y$, más allá de los diferentes sistemas morales, con sus imposiciones y sus anatemas, supo situar la magnanimidad de una deidad suprema, comprensiva y tolerante con el hombre.

Ante la inevitable presencia de la muerte, Yourcenar piensa que ya los antiguos y los orientales habían desarrollado una filosofía propia que tendía a considerar ciclos vitales y cambios que se producían en el seno de lo inmóvil. Frente a un continuo fluir, se sitúa el hombre y se perpetúa a sí mismo en un incesante movimiento de continuidad. Así lo ve Alexis, cuando contempla a su hijo: Pertenecia a esta familia cayos miembros se transmiten preciosamente pensamientos tan antiguos que hoy están ya fuera de uso, igual que los trineos dorados o los coches de caballos. Descendía, como yo, de antepasados de Polonia, de Poblia y de Bohemia, tendria sus mismas pasiones, sus desalientos súbitos, su amor a la tristeza y a los placeres extravagantes, todas sus fatalidades a las que habría que añadir las mias ${ }^{21}$.

Asistimos así a una unión de generaciones, idea ésta recurrente en la obra de Yourcenar, una larga cadena que simboliza la esencia del hombre, atemporal y, en cierta medida, eterno, aunque cargando siempre con lo que genéticamente ha heredado. De este modo, la búsqueda de Alexis va más allá de una simple exposición de sus tendencias o de un alegato a favor de la homosexualidad: implica de lleno la esencia misma de lo humano, como es habitual en la práctica totalidad de las obras de Marguerite Yourcenar. El detonante de dicha indagación ha sido la pretendida separación entre materia y espiritu, y sus prolongaciones la han conducido a una meditación sobre la vida humana de indudable calado.

La ruptura con Mónica no hace más que reafirmar a Alexis en su soledad, en el sentimiento pesimista del paso del tiempo, permitiéndole una libertad hasta entonces desconocida, pero alejándolo de manera casi definitiva de toda emoción. Sensualidad y emotividad han de caminar a la par. Esto en lo que viene a decimos la autora, a la vez que su propuesta consiste en una anulación del sentimiento de culpa, en una aceptación del propio yo y en un reencuentro con la propia identidad. La plena realización del ser humano ha de pasar por su autoaceptación en todos los casos, y no sólo en el de los múltiples Alexis. No hay dada de que el cristianismo intentó que el alma humana volviese a un estado de inocencia prepúber-dice-, por lo demás imaginario más que real y muy alejado de la verdadera infancia; de que quiso, y en gran

${ }^{20}$ Cf. M.YOURCENAR, Alexis..., o,c., 128-129.

${ }^{21} \mathrm{Cf}, \mathrm{M}$. YOURCENAR. Alexis..., o.c., 155. 
parte realizó, una desacralización de lo sensual, fuera del matrimonio, y que incluso en este último caso lo rodeó de tantas interdicciones que instaló a perpetuidad en la idea de sensualidad la nación de pecado".

Marguerite Yourcenar apuesta por una liberación de los estigmas de pecado que la ética imperante hace recaer sobre algunas conductas, y para ello recurre a mostrar otras culturas y otras formas de ver el mundo. Su táctica no se aleja mucho del relativismo de Montaigne y pretende derribar la certeza absoluta que el hombre occidental parece tener, su convencimiento de estar en posesión de la verdad absoluta. La condición humana es dispar y, a la vez, comuin, más allá de las aparentes disimilitudes y manifestaciones. Buscar la esencia de lo humano implica deshacerse de estereotipos e indagar en el incesante trabajo del hombre por conocerse y realizarse.

${ }^{2} \mathrm{CF}$. M. YOURCENAR, "Sobre unos cuantos temas eróticos y místicos de la Gita-Govinda", en El tiempo..., o.c., 122-123. 